Abstracta Iranica Abstracta Iranica

Revue bibliographique pour le domaine irano-aryen

Volume 28 | 2007

Comptes rendus des publications de 2005

\title{
«Iranians at War under Turkish Domination: the Example of Pre-Mongol Isfahan ». Iranian Studies, 38, 4, December 2005, pp. 587-606.
}

\section{Denise Aigle}

\section{(2) OpenEdition}

Journals

Édition électronique

URL : http://journals.openedition.org/abstractairanica/17372

DOI : 10.4000/abstractairanica. 17372

ISSN : 1961-960X

Éditeur :

CNRS (UMR 7528 Mondes iraniens et indiens), Éditions de l'IFRI

Édition imprimée

Date de publication : 15 mai 2007

ISSN : 0240-8910

Référence électronique

Denise Aigle, « « Iranians at War under Turkish Domination: the Example of Pre-Mongol Isfahan ». Iranian Studies, 38, 4, December 2005, pp. 587-606. », Abstracta Iranica [En ligne], Volume 28 | 2007, document 153, mis en ligne le 18 septembre 2007, consulté le 25 septembre 2020. URL : http:// journals.openedition.org/abstractairanica/17372; DOI : https://doi.org/10.4000/abstractairanica. 17372

Ce document a été généré automatiquement le 25 septembre 2020.

Tous droits réservés 


\title{
« Iranians at War under Turkish Domination: the Example of Pre- Mongol Isfahan ». Iranian Studies, 38, 4, December 2005, pp. 587-606.
}

\author{
Denise Aigle
}

Depuis les analyses pionnières de $\mathrm{Cl}$. Cahen (« Mouvements populaires et autonomisme urbain ", Arabica, 1958-9) et de J. Paul (Herrscher, Gemeinwesen, Vermittler: Ostiran und Transoxanien in vormongolischer Zeit, Stuttgart, 1996, cf. Abs. Ir. 20-21, c.r. $\mathrm{n}^{\circ}$ 241), on savait qu'à l'époque pré-mongole, les élites iraniennes disposaient d'un potentiel militaire qu'elles n'hésitaient pas à utiliser, parfois au service du prince, parfois contre lui. Dans cet article, Durand-Guédy approfondit la question à partir de l'exemple d'Isfahan durant la période seldjoukide. C'est un domaine qu'il connaît bien pour y avoir consacré ses recherches de doctorat (Aix-en-Provence, 2004, publication en cours). L'A. commence par expliquer que le sujet est difficile à appréhender : en effet, dans la mesure où la participation des habitants des villes aux opérations militaires contredisait le principe selon lequel la guerre était l'affaire du prince et de son armée, les auteurs de nos sources avaient tendance ou intérêt à la passer sous silence : le sujet n'était ni pertinent, ni légitime, sauf dans le cas du jihād, où toutes les forces de l'umma pouvaient être mobilisées (ce fut par exemple le cas dans la lutte contre les Ismaéliens, ou plus encore contre les Mongols). Concrètement, les élites urbaines avaient trois moyens à leur disposition pour jouer un rôle militaire. Le premier était le contrôle des murailles : en effet, il apparaît qu'aucun prince ne pouvait prétendre s'enfermer dans Isfahan s'il n'avait pas au préalable acquis le soutien de la population. Le second moyen était la mobilisation de milices. Celles-ci sont décrites explicitement à l'occasion de l'invasion mongole, mais Durand-Guédy montre que leur présence peut être mise en évidence tout au long de la période prise en compte. Le troisième moyen était la mise à profit d'un contexte politique particulièrement chaotique créé par le déclin, puis l'anéantissement, de l'autorité seldjoukide. Les élites urbaines savaient utiliser au mieux les dissensions entre les différentes forces turques qui s'affrontaient et 
n'hésitaient pas à s'allier à tel ou tel groupe pour l'emporter sur la scène politique locale. L'A. distingue "deux niveaux de luttes (l'un opposant les Turcs, l'autre les Iraniens) entre lesquels des connections se mettaient en place en fonction des intérêts respectifs des différents protagonistes" (p. 606). Cet article, qui synthétise certaines des conclusions de la thèse de l'A., donne un éclairage nouveau sur la première phase de la domination turque en Iran en réévaluant le rôle joué par les Iraniens.

INDEX

Thèmes : 4.1. Histoire médiévale

\section{AUTEURS}

DENISE AIGLE

EPHE / Orient-Méditerranée - Paris 